EPJ Web of Conferences 59, 03004 (2013)

DOI: $10.1051 /$ epjconf/20135903004

(C) Owned by the authors, published by EDP Sciences, 2013

\title{
Systematic analysis of direct-drive baseline designs for shock ignition with the Laser MégaJoule
}

\author{
V. Brandon ${ }^{1}$, B. Canaud ${ }^{1, a}$, S. Laffite ${ }^{1}$, M. Temporal ${ }^{2}$ and R. Ramis ${ }^{2}$ \\ ${ }^{1}$ CEA, DAM, DIF, 91297 Arpajon, France \\ ${ }^{2}$ ETSIA, Universidad Politécnica de Madrid, Spain
}

\begin{abstract}
We present direct-drive target design studies for the laser mégajoule using two distinct initial aspect ratios $(\mathrm{A}=34$ and $\mathrm{A}=5)$. Laser pulse shapes are optimized by a random walk method and drive power variations are used to cover a wide variety of implosion velocities between $260 \mathrm{~km} / \mathrm{s}$ and $365 \mathrm{~km} / \mathrm{s}$. For selected implosion velocities and for each initial aspect ratio, scaled-target families are built in order to find self-ignition threshold. High-gain shock ignition is also investigated in the context of Laser MégaJoule for marginally igniting targets below their own self-ignition threshold.
\end{abstract}

\section{INTRODUCTION}

Inertial confinement fusion (ICF) consists in illuminating a shell of fusible fuel with laser beams in direct-drive approach [1] or with X-ray in indirect drive approach [2]. Two laser facilities are built to achieve ICF with indirect drive configuration: the National Ignition Facility (NIF) in U.S.A. [3] and the Laser MégaJoule (LMJ) in France [4]. For LMJ, directly-driven self-ignition is possible [1] with indirect-drive beam geometry with zooming [5]. Moreover, Shock Ignition (SI) [6] and its application on LMJ [7] bring a new interest for direct-drive approach because it can offer high gain for non selfigniting target and allows to investigate the self-ignition threshold [8]. In this scheme, compression phase and ignition are separated. Usually, targets designs present high initial aspect ratio A, defined as the ratio of the deuterium-tritium (DT) ice-layer inner radius over the DT-ice layer thickness, around $\mathrm{A}=7$ for Fast-Ignition (FI) [9] or for Direct-Drive (DD) targets [1] and around A = 11 for indirect drive targets [4]. In our study, we explore low initial aspect ratios and moderate implosion velocities. Targets and laser pulses are optimized by a random-walk method and drive power variations in order to vary the implosion velocity. Then, selected target designs are scaled in Sec. 4 in order to scan the self-ignition threshold of transition between non- or marginally-igniting targets and burning targets, and finally shock ignition of marginally igniting targets at low implosion velocities is investigated.

\section{DIRECT-DRIVE BASELINE DESIGNS}

We set $\mathrm{A}=3$ and 5. Targets and laser pulses are described in Fig. 1. The initial aspect ratio considers only the $300 \mu \mathrm{g}$-DT ice-layer assuming that the polyimide $(\mathrm{CH})$ ablator is fully expanded at the end of the laser pulse. $\mathrm{CH}$ ablator thickness and drive power are initially given by Rocket-effect formulae [2] for an implosion velocity of $310 \mathrm{~km} / \mathrm{s}$ and assuming full ablation of $\mathrm{CH}$. Calculations are then performed using the one-dimensional (1D) Lagrangian radiation-hydrodynamics code FCI1 [10]. Laser pulse shapes are initially defined to achieve implosion velocities around $310 \mathrm{~km} / \mathrm{s}$ for each design and

\footnotetext{
${ }^{\mathrm{a}} \mathrm{e}$-mail: benoit. canaud@cea.fr
}

This is an Open Access article distributed under the terms of the Creative Commons Attribution License 2.0, which permits unrestricted use, distribution, and reproduction in any medium, provided the original work is properly cited. 

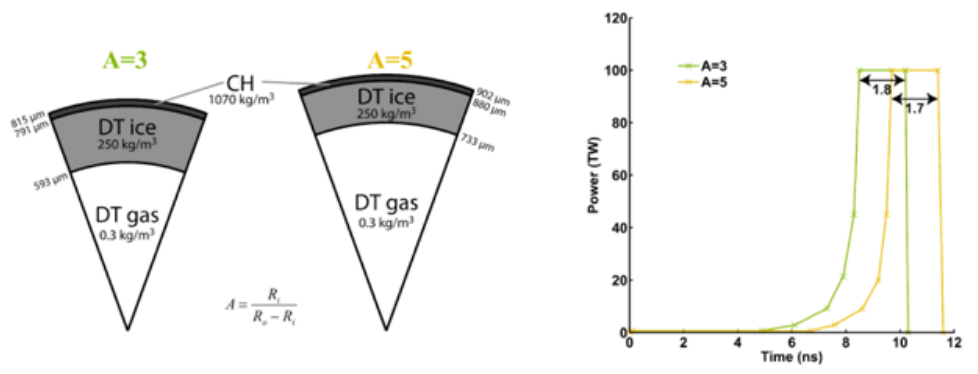

Figure 1. Targets designs (left) with $\mathrm{A}=3$ (left-green) and $\mathrm{A}=5$ (right-yellow) and laser pulses (right).


Figure 2. Thermonuclear energy versus implosion velocity for $\mathrm{A}=3$ (left) and $\mathrm{A}=5$ (right). Colored points are given in Table 1.

follow a Kidder-like law [11] to minimize entropy during the whole compression phase. The foot is chosen to get an inflight adiabat of one in the fuel layer. Drive duration is constant in our study and is sized to correspond to the ablator thickness with laser power drive of $100 \mathrm{TW}$. This first optimization is complemented by a random-walk method that consists in varying the pulse ramp in order to obtain a refined shock timing that maximizes the areal density at stagnation of non-igniting targets or the thermonuclear energy when target ignites. The drive power also varies. A new laser pulse is built for each random realization. Successive refinements of intervals are used to cover unexplored part of the parameter space and to get an optimum. The results are shown in Fig. 2 where thermonuclear energy is given versus implosion velocity for each aspect ratio. Each dot represents a 1D-implosion. Self ignition threshold is observed for an implosion velocity of $300 \mathrm{~km} / \mathrm{s}$ for $\mathrm{A}=3$, and $325 \mathrm{~km} / \mathrm{s}$ for $\mathrm{A}=5$. Thus, with the same fuel mass, the self-ignition kinetic-threshold is lower for $A=3$ than for $A=5$. We notice that the absorbed laser energy is higher for $\mathrm{A}=3$ than for $\mathrm{A}=5$ for the same implosion velocity. Thus the thermonuclear gain, above ignition, is roughly the same for both aspect ratios but not at the same implosion velocity (cf Table1).

\section{SCALED TARGETS}

We selected a few designs at the frontier of the data clouds for both A that are marked by colored points in Fig. 2. These points, summarized in Table 1, offer the maximum areal density (under self ignition threshold) or maximum thermonuclear energy (above self ignition threshold), with minimum absorbed energy for different implosion velocities. The average peak areal density is higher for $\mathrm{A}=3$ $\left(\rho r \simeq 19 \mathrm{~kg} / \mathrm{m}^{2}\right)$ than for $\mathrm{A}=5\left(\rho r \simeq 16 \mathrm{~kg} / \mathrm{cm}^{2}\right)$. An Eulerian scaling [12] is applied to the previous set of designs that conserves velocities and laser intensities to explore thermonuclear energy as a 
Table 1. List of working points selected to compute scaled targets.

\begin{tabular}{cccc|cccc} 
& \multicolumn{2}{c}{$\mathbf{A = 3}$} & \multicolumn{4}{c}{$\mathbf{A = 5}$} \\
$\mathrm{V}$ & $E_{a}$ & $\rho R$ & $E_{t h}$ & $\mathrm{~V}$ & $E_{a}$ & $\rho R$ & $E_{t h}$ \\
$(\mathrm{~km} / \mathrm{s})$ & $(\mathrm{kJ})$ & $\left(\mathrm{kg} / \mathrm{m}^{2}\right)$ & $(\mathrm{kJ})$ & $(\mathrm{km} / \mathrm{s})$ & $(\mathrm{kJ})$ & $\left(\mathrm{kg} / \mathrm{m}^{2}\right)$ & $(\mathrm{kJ})$ \\
& & & & $\mathbf{2 8 0}$ & 171 & 1.46 & 12 \\
$\mathbf{2 8 6}$ & 215 & 18.5 & 18 & $\mathbf{2 8 9}$ & 181 & 15.0 & 21 \\
$\mathbf{2 9 4}$ & 233 & 18.8 & 15 & $\mathbf{2 9 4}$ & 187 & 15.3 & 25 \\
$\mathbf{2 9 7}$ & 238 & 18.4 & 29 & $\mathbf{2 9 8}$ & 193 & 15.6 & 32 \\
$\mathbf{3 0 6}$ & 234 & 18.6 & 573 & $\mathbf{3 0 3}$ & 199 & 15.8 & 49 \\
$\mathbf{3 0 8}$ & 250 & 18.7 & 8389 & $\mathbf{3 0 8}$ & 204 & 15.9 & 44 \\
$\mathbf{3 1 4}$ & 260 & 18.2 & 23032 & & & & \\
$\mathbf{3 2 0}$ & 272 & 18.6 & 26216 & $\mathbf{3 1 7}$ & 219 & 16 & 234 \\
$\mathbf{3 2 5}$ & 283 & 18.9 & 26915 & $\mathbf{3 2 9}$ & 226 & 16 & 18119 \\
& & & & $\mathbf{3 3 3}$ & 233 & 16.4 & 21411 \\
& & & & $\mathbf{3 4 8}$ & 249 & 16.6 & 24862 \\
& & & & $\mathbf{3 5 2}$ & 264 & 16.4 & 25064 \\
& & & & $\mathbf{3 5 6}$ & 267 & 16.6 & 25695 \\
& & & & $\mathbf{3 6 5}$ & 280 & 16.7 & 26296
\end{tabular}
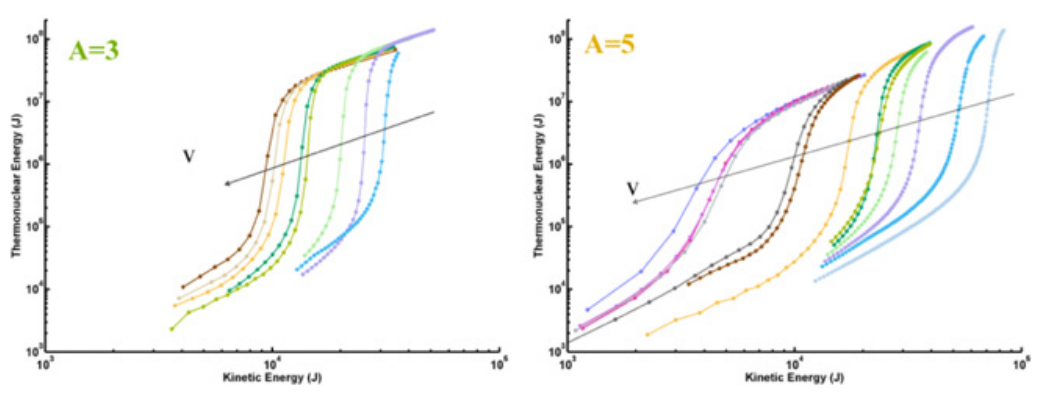

Figure 3. Thermonuclear energy as function of kinetic energy for $A=3$ (left) and $A=5$ (right). Each curve is scaled from a selected point described in Table 1.

function of kinetic energy (cf Fig. 3). Scaling laws are expressed in function of a scale factor f: $m_{1} / m_{0}=f, E_{1} / E_{0}=f, r_{1} / r_{0}=f^{1 / 3}, t_{1} / t_{0}=f^{1 / 3}, P_{\text {laser } 1} / P_{\text {laser } 0}=f^{2 / 3}, V_{1} / V_{0}=1, \rho_{1} / \rho_{0}=1$, and $I_{1} / I_{0}=1$. Self-ignition is always achieved for all curves with a kinetic self-ignition threshold which decreases with the implosion velocity. Such preliminary results are very promising and will be deeply detailed in a future article.

\section{SHOCK IGNITION}

The shock ignition scheme [6] consists in adding a high power spike at the end of the drive pulse. This spike creates a strong shock that propagates towards the hot spot which departs from an isobaric stagnation, and reduces the ignition threshold. Spike timing must be adjusted in function of the spike power as shown in Fig. 4. This approach is applied to a marginally-igniting target that is under its selfignition threshold for $\mathrm{A}=5$ and $v=317 \mathrm{~km} / \mathrm{s}$ (here, $f=0.7$ ). Figure 4 represents the ignition window. Thermonuclear gain $(\sim 90)$, defined as the ratio of thermonuclear energy over the absorbed energy, is exactly the same as the one obtained for the self-igniting target, when $f=1$. Indeed, thermonuclear energy is roughly $17 \mathrm{MJ}$ for $180 \mathrm{~kJ}$ of absorbed energy and a DT-mass of $210 \mu \mathrm{g}$. 


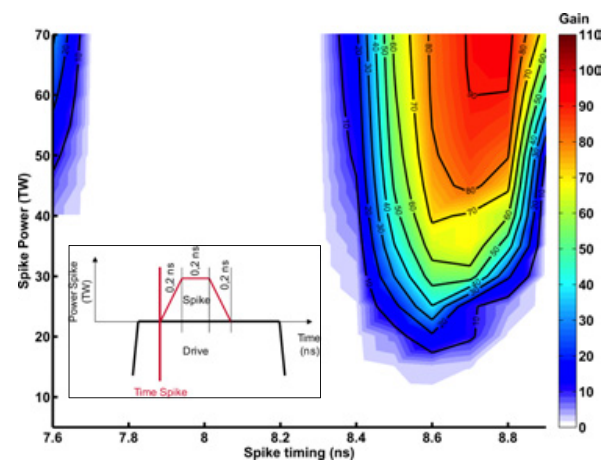

Figure 4. 1D gain versus spike power and time-of-launch for $\mathrm{A}=5, \mathrm{f}=0.7$, and $\mathrm{V}=317 \mathrm{~km} / \mathrm{s}$.

\section{CONCLUSION}

We present preliminary results about two new families of target designs with initial aspect ratios A of 3 and 5. A large range of peak implosion velocities is explored by the means of a random walk method. Self-ignition is obtained at a higher implosion velocity for $\mathrm{A}=5$ than for $\mathrm{A}=3$. Selected points are identified that maximize thermonuclear energy and peak areal densities for given absorbed energies. Scaling laws that conserve implosion velocities are applied to this set of selected designs that allow to compose a large library of target designs in function of initial aspect ratio, peak implosion velocity, fuel mass and position relative to self-ignition threshold. Finally, shock ignition is considered for a reducedsize marginally-igniting target that produces a 1D gain of 93.

\section{References}

[1] B. Canaud, F. Garaude, C. Clique, N. Lecler, A. Masson, R. Quach and J. Van der Vliet, Nucl. Fusion 47, 1652 (2007)

[2] J. D. Lindl, P. Amendt, R. L. Berger, S.G. Glendinning, S.H. Glenzer, S. W. Haan, L. Kauffman, L. Landen and L. J. Suter, Phys. Plasmas 11, 339 (2004)

[3] E. I. Moses, Energy Conversion and Management 49, 1795 (2008)

[4] J. Giorla, J. Bastian, C. Bayer, B. Canaud, M. Casanova, F. Chaland, C. Cherfils, C. Clique, E. Dattolo, P. Fremerye, D. Galmiche, F. Garaude, P. Gauthier, S. Laffite, N. Lecler, S. Liberatore, P. Loiseau, G. Malinie, L. Masse, A. Masson, M. C. Monteil, F. Poggi, R. Quach, F. Renaud, Y. Saillard, P. Seytor, M. Vandenboomgaerde, J. Van der Vliet and F. Wagon, Plasm. Phys. Control. Fusion 48, B75 (2006)

[5] B. Canaud and F. Garaude, Nucl. Fusion 45, L43 (2005)

[6] R. Betti, C. D. Zhou, K. S. Anderson, L. J. Perkins, W. Theobald and A. A. Solodov, Phys. Rev. Lett. 98, 155001 (2007)

[7] B. Canaud, S. Laffite, V. Brandon, and M. Temporal, Las. Part. Beams 30, 183 (2012)

[8] B. Canaud and M. Temporal, New J. Phys. 12, 3037 (2010)

[9] S. Atzeni, A. Schiavi and C. Bellei, Phys. Plasmas 14, 2702 (2007)

[10] E. Buresi, J. Coutant, R. Dautray, M. Decroisette, B. Duborgel, P. Guillaneux, J. Launspach, P. Nelson, C. Patou, J. M. Reisse and J. P. Watteau, Las. Part. Beams 4, 531 (1986)

[11] R. E. Kidder, Nucl. Fusion 16, 405 (1976)

[12] E. Falize, S. Bouquet and C. Michaut, Astrophys. Space Sci. 322, 107 (2009) 